\title{
Overview of Methods of Analysis of Beams on Elastic Foundation
}

\author{
Karmvir Tiwari ${ }^{1}$, Ramakrishna Kuppa ${ }^{2}$ \\ ${ }^{I}$ (PG Student, Department of Mechanical Engineering, Sreenidhi Institute of Science \& Technology, Hyderabad, \\ Telangana State, India-501301) \\ ${ }_{2}^{2}$ (Associate Professor, Department of Mechanical Engineering, Sreenidhi Institute of Science \& Technology, \\ Hyderabad, Telangana State, India-501301)
}

\begin{abstract}
In this paper, the response of a beam on elastic foundation under static and dynamic loads is studied. The foundation model is based on Winkler hypothesis. Various methods are described for treating the analysis of beams on elastic foundation subjected to point load in transverse direction. An example problem is solved using finite element package ANSYS.
\end{abstract}

Keywords: Beam on Winkler foundation, dynamic analysis, moving loads, fem formulation

\section{INTRODUCTION}

The need for the study arose while analyzing the conveyor galleries supported on trestles in coal power plants. Earlier research suggests that these galleries can be treated as beams on elastic foundation. Beams on elastic foundation is treated by engineers and researchers before but it is not discussed in this context. This paper details the methods to analyze such beams subjected to various load cases. Roland Jančo[1] described numerical methods for solution of beams and frames on elastic foundation subjected to static load. He suggests that elastic foundation can be approximated by springs of equal stiffness. His work is reviewed in this paper for an example problem. Thambiratnam \& Zhuge[2] studied the dynamics of beams on an elastic foundation and subjected to moving loads by using the finite element method. Transient response of beam with elastic foundation by Yi Wang, Yong Wong[3] discusses effect of various parameters on dynamic behaviour of beam under point load and pressure load. Serdar Hügül[4] in vibration analysis of systems subjected to moving loads discussed dynamic response of beams and frames which are subjected to moving loads using finite element method and Newmark integration method. Y. Yeşilce[5] investigated the dynamic analysis of a free beam subjected to transverse forces and moments on an elastic soil. They transformed concentrated disturbances on beams to distributed loads using Dirac distribution theory to use differential equation of beam on elastic foundation established for distributed loads. Analytical methods for dynamic load cases are described in Vibration of solids and structures by L Fryba[6]. Though analytical results exist for beams on elastic foundation acted upon by moving loads, it has not been implemented using existing finite element packages. This paper includes solution of an example problem using finite element package ANSYS.

\section{METHODS OF ANALYSIS}

Analytical and finite element approach to solve beam on elastic foundation are described in this section. Analytical approach involves formation of governing differential equations and apply boundary conditions to obtain constants of integration

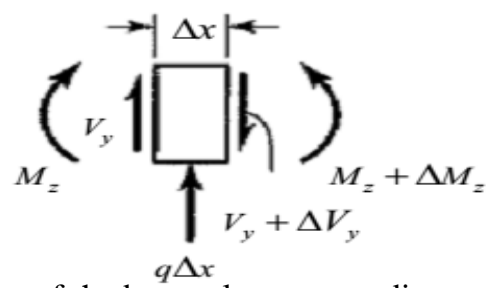

Fig1. Free Body Diagram of the beam element at a distance $\mathrm{x}$ from end

Governing differential equations for various load cases are described as follows:

Case1 A constant point load at center

$$
E I \frac{d^{4} v}{d x^{4}}+k v=0
$$

; $\mathrm{E}=$ Young's modulus of the material

I= Area moment of inertia of the cross-section of the beam 
$\mathrm{k}=$ coefficient of winkler foundation $\left(\mathrm{N} / \mathrm{m}^{2}\right)$

$\mathrm{v}=$ deflection of the beam in transverse direction

Case2 Harmonic point load at center

$$
E I \frac{d^{4} v}{d x^{4}}+k v=F \cos (\omega \mathrm{t})
$$

; $\mathrm{F}=$ magnitude of the force

$\omega=$ frequency of oscillation

$\mathrm{t}=$ time.

Case 3 Constant load travelling over beam with constant velocity

$$
E I \frac{d^{4} v(x, t)}{d x^{4}}+m_{b} \frac{\partial^{2} v(x, t)}{\partial t^{2}}+k v=\delta(x-c \mathrm{t}) \mathrm{F}
$$

; $m_{b}=$ mass of the beam per unit length

$\delta=$ Dirac function expressing spatial variation of load

$\mathrm{c}=$ velocity of load.

Case4 Harmonic load travelling over beam with constant velocity

$$
E I \frac{d^{4} v(x, t)}{d x^{4}}+m_{b} \frac{\partial^{2} v(x, t)}{\partial t^{2}}+k v=\delta(x-c t) \mathrm{F} \cos (\omega \mathrm{t})
$$

It is to be noted that damping effects of any kind and inertia effects of the moving load are ignored while forming the differential equation. These can be solved with appropriate boundary conditions for each case to obtain the deflection, slope and other parameters.

Finite element approach involves formation of mass, stiffness, and force matrices and using the governing equation

$$
[M]\left\{\mathrm{v}^{\prime \prime}\right\}+[K]\{\mathrm{v}\}=\{f\}
$$

If damping is considered then the term $[\mathrm{C}]\left\{\mathrm{v}^{\prime}\right\}$ is considered to account for damping in the equation. $\{\mathrm{v}\},\left\{\mathrm{v}^{\prime}\right\},\left\{\mathrm{v}^{\prime \prime}\right\}$ are the displacement, velocity and acceleration vectors respectively. $[\mathrm{M}],[\mathrm{K}]$ are the mass, stiffness matrices. $\{\mathrm{f}\}$ is a force vector.

Mass matrix is obtained by considering kinetic energy of a beam element of length $l$ as follows:

$$
\begin{aligned}
T & =\frac{1}{2} \rho A \int\left(v^{\prime}\right)^{T} d x\left(v^{\prime}\right) \\
\text { or } T & =\frac{1}{2} \rho A \int_{0}^{l}\left(\mathrm{q}^{\prime}\right)^{T}(N)^{T}(N)\left(\mathrm{q}^{\prime}\right) d x \\
\text { or } T & =\frac{1}{2}\left(\mathrm{q}^{\prime}\right)^{T} \cdot \rho A \int_{0}^{l}(N)^{T}(N) d x \cdot\left(\mathrm{q}^{\prime}\right) \\
\text { or } T & =\frac{1}{2}\left(\mathrm{q}^{\prime}\right)^{T} .(\mathrm{M}) \cdot\left(\mathrm{q}^{\prime}\right)
\end{aligned}
$$

Mass of the element is given by $M=\rho A \int_{0}^{l}(N)^{T}(N) d x$

; $\rho=$ Density of the beam

$A=$ Area of the cross section

$v^{\prime}=$ Velocity of the element in transverse direction

$\mathrm{q}^{\prime}=$ Nodal velocity

$(N)=$ Shape function matrix 


$$
\text { or }(N)=\left(1-3 \cdot \frac{x^{2}}{l^{2}}+2 \cdot \frac{x^{3}}{l^{3}} \quad x-2 \cdot \frac{x^{2}}{l}+\frac{x^{3}}{l^{2}} \quad 3 \cdot \frac{x^{2}}{l^{2}}-2 \cdot \frac{x^{3}}{l^{3}} \quad-\frac{x^{2}}{l}+\frac{x^{3}}{l^{2}}\right)
$$

Therefore, Elemental Mass Matrix is

$$
M=\frac{\rho A L}{420}\left[\begin{array}{cccc}
156 & 22 l & 54 & -13 l \\
22 l & 4 l^{2} & 13 l & -3 l^{2} \\
54 & 13 l & 156 & -22 l \\
-13 l & -3 l^{2} & -22 l & 4 l^{2}
\end{array}\right]
$$

Stiffness matrix is obtained by combing the bending stiffness matrix with the foundation stiffness matrix. Bending stiffness matrix is given by $\left[K_{b}\right]=\int_{0}^{l}[B]^{T} E I[B] d x$

$$
; B=\frac{d^{2} N}{d x^{2}}, \mathrm{~N} \text { is the shape function matrix }
$$

Therefore Bending Stiffness Matrix is given by

$$
\left[\mathbf{K}_{b}\right]=\frac{E I}{l^{3}}\left[\begin{array}{cccc}
12 & 6 l & -12 & 6 l \\
6 l & 4 l^{2} & -6 l & 2 l^{2} \\
-12 & -6 l & 12 & -6 l \\
6 l & 2 l^{2} & -6 l & 4 l^{2}
\end{array}\right]
$$

Beam on Winkler's foundation behaves as shown in Fig2 under pressure. It can be interpreted as a system of mutually independent springs.

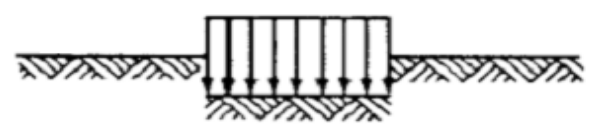

Fig2. Deflection of Winkler's foundation under pressure

A differential area dA which deflects laterally under pressure behaves as a spring with stiffness $\left(\mathrm{k}_{0}\right) \mathrm{dA}$. Foundation stiffness is obtained by writing expression for strain energy $(\mathrm{U})$ of the element.

$$
\begin{gathered}
U=\frac{1}{2} \int k_{o} d A \cdot v^{2} \\
\text { or } U=\frac{1}{2} \int v^{T} k_{o} v d A \\
\text { or } U=\frac{1}{2} \int_{0}^{l}\left(q_{f}\right)^{T}\left[\mathrm{~N}_{f}\right]^{T} k_{o}\left[\mathrm{~N}_{f}\right]\left(q_{f}\right) b d x \\
\text { or } U=\frac{1}{2}\left(q_{f}\right)^{T}\left[\mathrm{~K}_{f}\right]\left(q_{f}\right) \\
; k_{e}=\text { Foundation modulus }\left(\mathrm{N} / \mathrm{m}^{3}\right) \\
q_{f}=\text { Nodal displacement } \\
v=\text { Displacement of the differential element }
\end{gathered}
$$

Foundation stiffness is given by $\left[\mathrm{K}_{f}\right]=b k_{o} \int_{0}^{l}\left[\mathrm{~N}_{f}\right]^{T}\left[\mathrm{~N}_{f}\right] d x$

$$
;\left[N_{f}\right]=[N]
$$


Therefore, foundation stiffness matrix is

$$
\left[\mathbf{K}_{\mathrm{f}}\right]=\left[\begin{array}{cccc}
\frac{13 b l k}{35} & \frac{11 b l^{2} k}{210} & \frac{9 b l k}{70} & -\frac{13 b l^{2} k}{420} \\
\frac{11 b l^{2} k}{210} & \frac{b l^{3} k}{105} & \frac{13 b l^{2} k}{420} & -\frac{b l^{3} k}{140} \\
\frac{9 b l k}{70} & \frac{13 b l^{2} k}{420} & \frac{13 b l k}{35} & -\frac{11 b l^{2} k}{210} \\
-\frac{13 b l^{2} k}{420} & -\frac{b l^{3} k}{140} & -\frac{11 b l^{2} k}{210} & \frac{b l^{3} k}{105}
\end{array}\right]
$$

Stiffness matrix of beam on elastic foundation $\left[K_{b e f}\right]$ is obtained by combining $\left[K_{b}\right]$ and $\left[K_{f}\right]$.

$$
\begin{aligned}
& {\left[K_{b e f}\right]=\left[K_{b}\right]+\left[K_{f}\right] } \\
{\left[K_{b e f}\right]=} & {\left[\begin{array}{cccc}
K_{1,1} & K_{1,2} & K_{1,3} & K_{1,4} \\
K_{1,2} & K_{2,2} & -K_{1,4} & K_{2,4} \\
K_{1,3} & -K_{1,4} & K_{1,1} & -K_{1,2} \\
K_{1,4} & K_{2,4} & -K_{1,2} & K_{2,2}
\end{array}\right] }
\end{aligned}
$$

Beam on elastic foundation can also be treated like beam supported on springs of equivalent stiffness. Stiffness matrix of such beam is formed by combining spring stiffness with the beam stiffness. In connection with conveyor galleries in coal power plants, gallery can be treated like a beam and supporting trestle can be replaced by a spring with equivalent stiffness. Stiffness of the trestle can be found by applying a unit load and taking reciprocal of deflection.

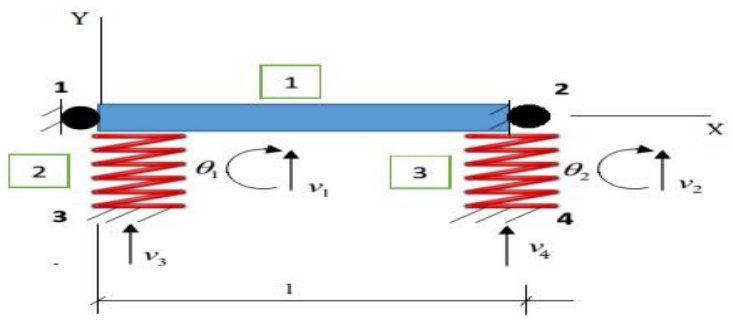

Fig3. Beam supported on springs

Stiffness matrix of the spring corresponding to the nodes 1,2,3,4 as shown in Fig.3 is

As foundation is replaced by two springs

$$
\left[K_{c}\right]=\left[\begin{array}{cccc}
k_{c} & 0 & -k_{c} & 0 \\
0 & k_{c} & 0 & -k_{c} \\
-k_{c} & 0 & k_{c} & 0 \\
0 & -k_{c} & 0 & k_{c}
\end{array}\right]
$$

$$
k_{c}=\frac{\text { Foundation stiffness }}{\text { Number of springs }}=\frac{k_{o}}{2}
$$

Stiffness of beam on springs is

$$
\left[K_{s}\right]=\left[K_{c}\right]+\left[K_{b}\right]
$$

Taking $k_{m}=\frac{l^{3}}{E I} k_{c}$ as the modified spring stiffness, stiffness matrix of the beam supported on springs can be written as: 


$$
\left[K_{s}\right]=\left[\begin{array}{cccccc}
12+k_{m} & 6 l & -12 & 6 l & -k_{m} & 0 \\
6 l & 4 l^{2} & -6 l & 2 l^{2} & 0 & 0 \\
-12 & -6 l & 12+k_{m} & -6 l & 0 & -6 l \\
6 l^{2} & 2 l^{2} & -6 l & 4 l^{2} & 0 & 0 \\
-k_{m} & 0 & 0 & 0 & k_{m} & 0 \\
0 & 0 & -k_{m} & 0 & 0 & k_{m}
\end{array}\right]
$$

Force vector for a point load travelling over beam is obtained as $\{f\}=\left[N_{d}\right]^{T} F$ where $\left[N_{d}\right]^{T}$ represents shape function evaluated at the position of the force F. For $\mathrm{n}$ degrees of freedom, it is a $\mathrm{n} \mathrm{X} 1$ vector which contains all zeros except for a 4 X 1 sub-vector.

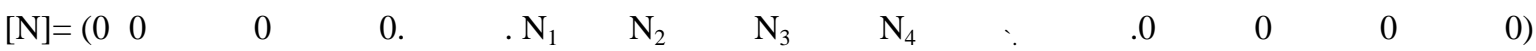

This $4 \mathrm{X} 1$ nonzero sub-vector corresponds to the degrees of freedom of the element on which the force is acting. It is time dependent as it changes as the load moves from one element to another with time. $\mathrm{N}_{1}, \mathrm{~N}_{2}, \mathrm{~N}_{3}, \mathrm{~N}_{4}$ are the shape functions of the element as discussed before.

\section{CASE STUDY}

Consider a beam of dimension $3.6 \mathrm{~m} \times 0.2 \mathrm{~m} \times 0.4 \mathrm{~m}$ with foundation modulus $1 \mathrm{e}+8 \mathrm{~N} / \mathrm{m}^{3}$ subjected to load cases described earlier in the paper. Magnitude of the load is $1 \mathrm{e}+5 \mathrm{~N}$.

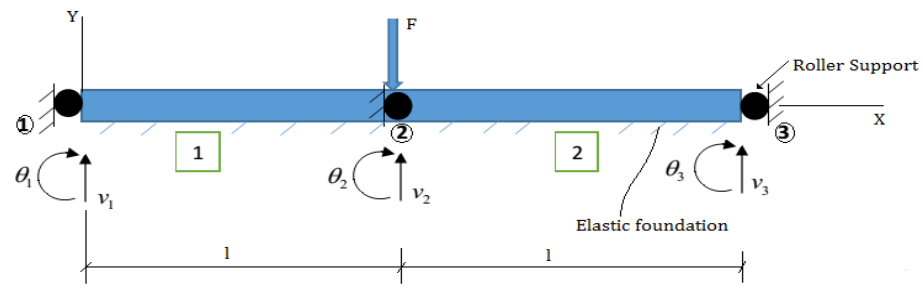

Fig4 Model of the beam (Load case1)

The problem is solved using finite element package ANSYS. The results are listed as follows:

Load Case1. Point Load acting at center of the beam (Static Case):

A beam is modelled with two equal elements. A point load of constant magnitude $(1 \mathrm{e} 5 \mathrm{~N})$ acts at the centre. In the table, -ve sign for downward displacement and +ve sign for upward displacement.

Table1. Max, Min values under static load

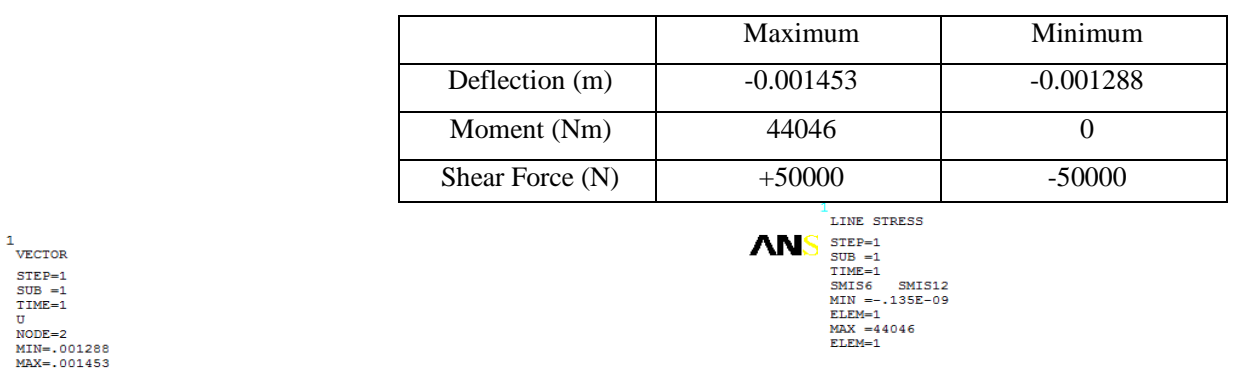
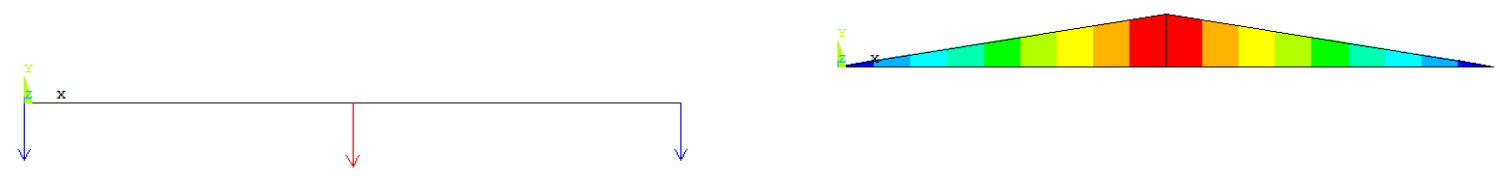

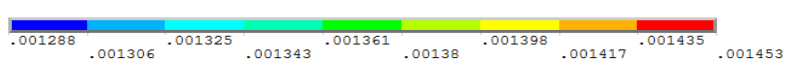

Fig5 Deflection Diagram (m)

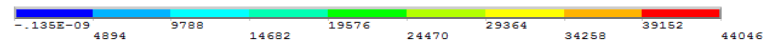

Fig6 Bending Moment Diagram 


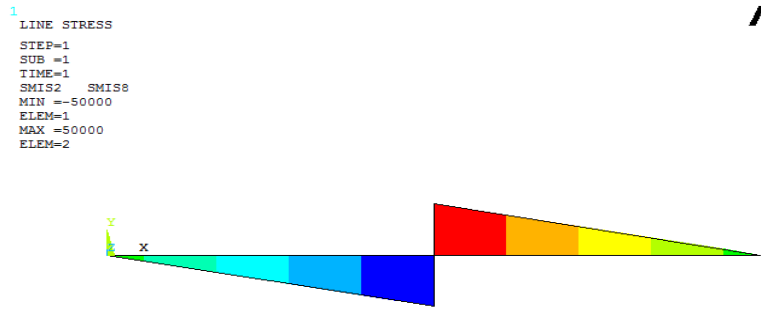

Fig7 Shear Force Diagram

Load Case2. Harmonic Load acting at center of the beam (Temporal Variation):

Load at centre of the beam varies with circular frequency. The frequency ranges from 0 to $10 \mathrm{rad} / \mathrm{s}$.

Table2. Deflection $(\mathrm{m})$ under oscillating load

\begin{tabular}{|l|l|l|}
\hline Frequency(1-10 rad/s) & Maximum & Minimum \\
\hline Left End Node & -0.00148384 & -0.00128944 \\
\hline Centre Node & -0.00165013 & -0.00145507 \\
\hline Right End Node & -0.00148384 & -0.00128944 \\
\hline
\end{tabular}

AMPLITUDE

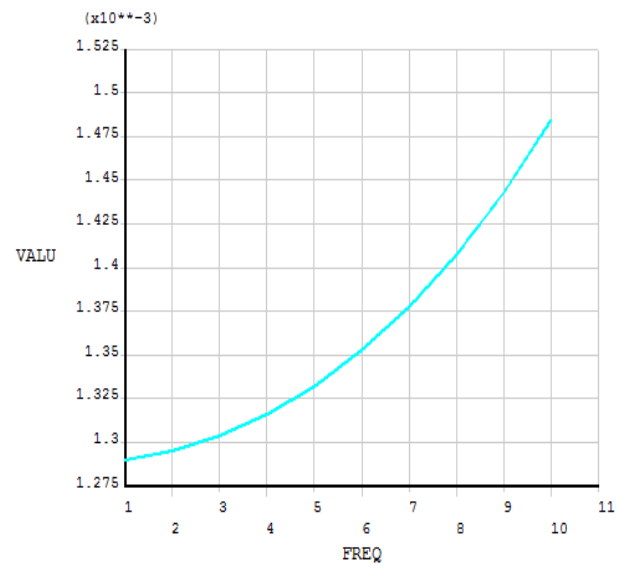

Fig8 Deflection of Left End Node (m)

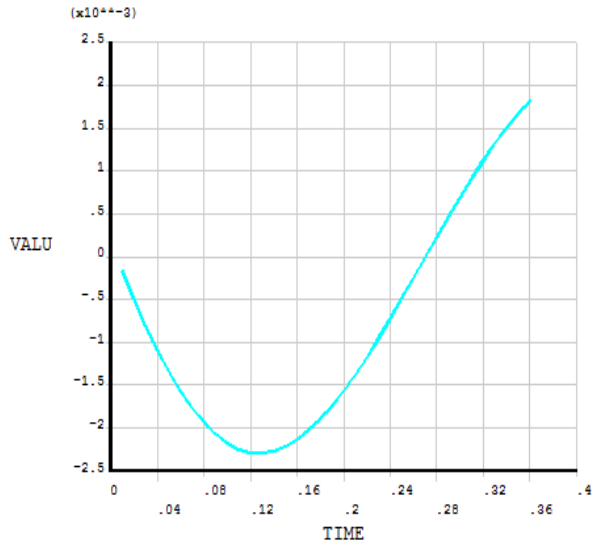

Fig9 Deflection of Center Node (m)

POST26

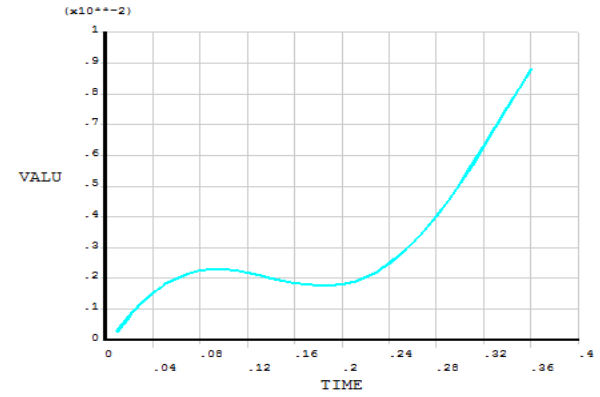

Fig10. Deflection of Right End Node (m) 
Load Case3. Constant load travelling over beam with constant velocity at $10 \mathrm{~m} / \mathrm{s}$ (Spatial Variation):

Beam is modelled with 10 elements. A constant load traverses the beam with a speed of $10 \mathrm{~m} / \mathrm{s}$ in $0.36 \mathrm{~s}$ with time steps of $0.01 \mathrm{~s}$.

Table3. Deflection (m) under spatial load

\begin{tabular}{|l|l|l|}
\hline Time(0.01-0.36s) & Maximum & Minimum \\
\hline Left End Node & -0.00954192 & -0.000610263 \\
\hline Centre Node & -0.00532779 & -0.000171425 \\
\hline Right End Node & -0.00821799 & 0.0026218 \\
\hline
\end{tabular}

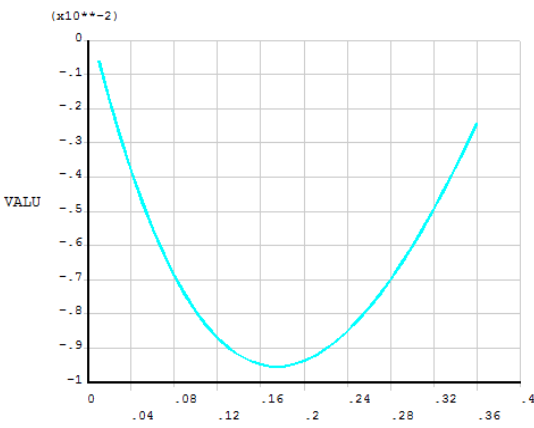

Fig11 Deflection of Left End Node (m)

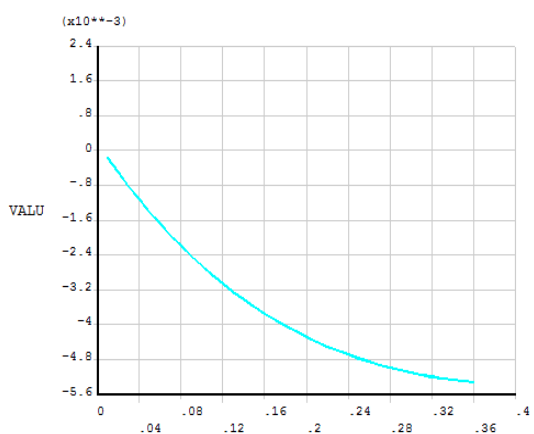

Fig12 Deflecetion of Center Node (m)

POST26

\section{$\mathbf{N}$}

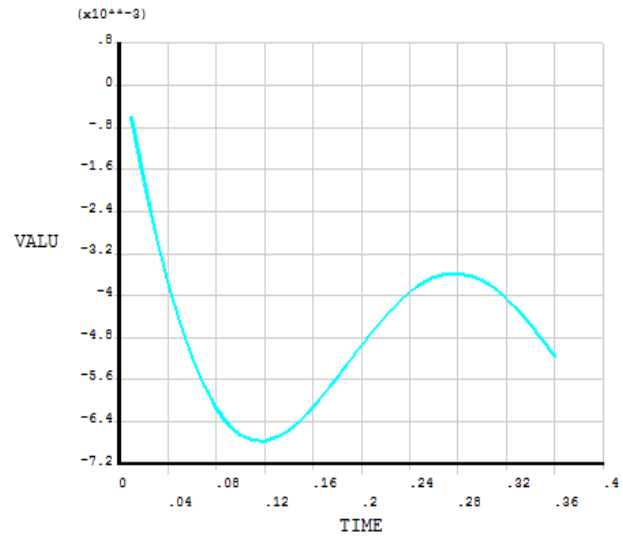

Fig13 Deflection of Right End Node (m)

Load Case4. Harmonic load travelling over beam with constant velocity at $10 \mathrm{~m} / \mathrm{s}$ (Spatial+ Temporal Variation): Beam is modelled with 10 elements. A load whose magnitude $(1 \mathrm{e} 5 \mathrm{~N})$ varies as a cosine function with constant frequency of $10 \mathrm{rad} / \mathrm{s}$ traverses the beam with a speed of $10 \mathrm{~m} / \mathrm{s}$ in $0.36 \mathrm{~s}$ with time steps of $0.01 \mathrm{~s}$.

Table4. Deflection $(\mathrm{m})$ under spatial+ temporal load

\begin{tabular}{|l|l|l|}
\hline Time(0.01-0.36s) & Maximum & Minimum \\
\hline Left End Node & -0.00676691 & -0.000607214 \\
\hline Centre Node & -0.00229245 & 0.00181616 \\
\hline Right End Node & 0.00879352 & 0.00026303 \\
\hline
\end{tabular}




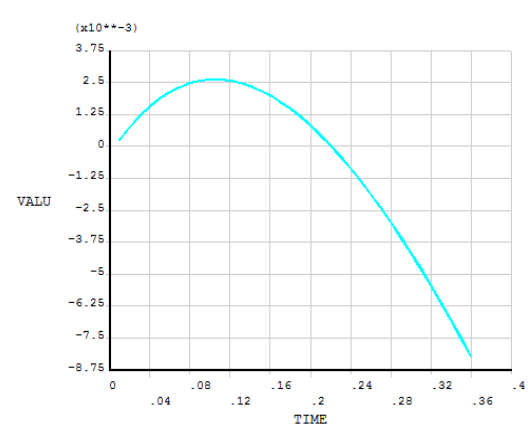

Fig14 Deflection of Left End Node (m)

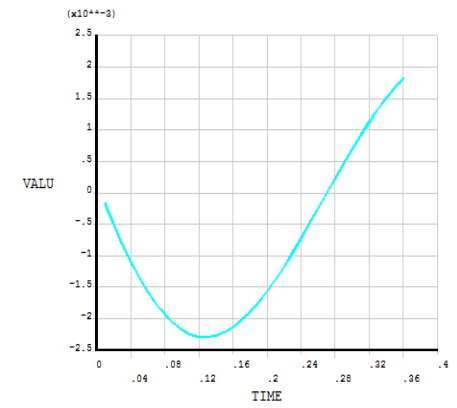

Fig15 Deflection of Center Node (m)

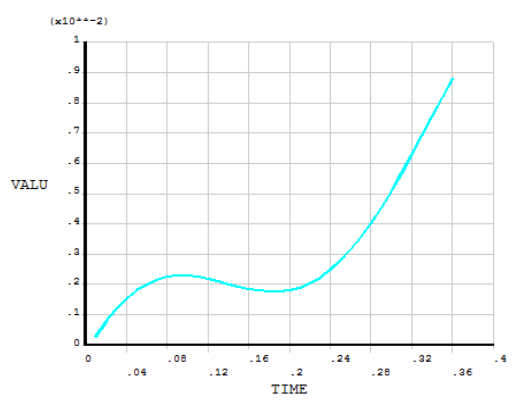

Fig16 Deflection of Right End Node (m)

Load Cases 1, 2 are solved using three elements whereas Load Cases 3, 4 are solved using ten elements for accuracy. With increasing number of divisions accuracy improves but time for computation increases.

\section{CONCLUSION}

The methods of analysis of beams on elastic foundation are studied. The finite element method for static and dynamic analysis of beam is provided in detail. An example is taken and solved for both static and dynamic loading. The results show the behavior of beams on elastic foundation when subjected to loads with spatial and temporal variation. This provides a groundwork to study structures on continuous foundations.

Proceedings Papers:

\section{REFERENCES}

[1] Roland Jančo, Solution Methods for Beam and Frames on Elastic Foundation Using the Finite Element Method. International Scientific Conference, Ostrava, 2010

Journal Papers:

[2] D. Thambiratnam and Y. Zhuge, Dynamic Analysis of Beams on an Elastic Foundation Subjected to Moving Loads. Journal of Sound and Vibration, 198(2), 1996, 149-169

[3] Yi Wang, Yong Wang, Biaobiao Zhang and Steve Shepard, Transient Responses of Beam with Elastic Foundation Supports under Moving Wave Load Excitation. International Journal of Engineering and Technology, 2011, Volume 1No. 2

\section{Theses:}

[4] Serdar Hügül, Vibration Analysis of Systems Subjected To Moving Loads By Using The Finite Element Method, Dokuz Eylül University, Izmir, 2005.

[5] Y. Yeşilce, Dynamic Analysis of Foundation Beams Subjected to Transverse Loading on Winkler Soil, Dumlupınar Üniversitesi, Turkey, 2006.

Books:

[6] Ladislav Fryba, Vibrations of solids and structures under moving loads (Czech Republic, Thomas Telford House, 1999) 